\title{
Choosing and refusing: doxastic voluntarism and folk psychology
}

\author{
John Turri' ${ }^{1,2}$ - David Rose $^{3} \cdot$ Wesley Buckwalter ${ }^{1}$
}

(C) Springer Science+Business Media B.V. 2017

\begin{abstract}
A standard view in contemporary philosophy is that belief is involuntary, either as a matter of conceptual necessity or as a contingent fact of human psychology. We present seven experiments on patterns in ordinary folk-psychological judgments about belief. The results provide strong evidence that voluntary belief is conceptually possible and, granted minimal charitable assumptions about folkpsychological competence, provide some evidence that voluntary belief is psychologically possible. We also consider two hypotheses in an attempt to understand why many philosophers have been tempted to view belief as involuntary: that belief is a prototype concept and that belief is a dual character concept. Altogether, our findings contribute to longstanding philosophical debates about the relationship between the will and the intellect, while also advancing scientific understanding of important social judgments.
\end{abstract}

Keywords Voluntarism · Involuntarism · Belief · The will · Folk psychology · Dual character concepts

Electronic supplementary material The online version of this article (doi:10.1007/s11098-017-0970-x) contains supplementary material, which is available to authorized users.

John Turri

john.turri@gmail.com

1 Philosophy Department, University of Waterloo, 200 University Avenue West, Waterloo, ON N2L3G1, Canada

2 Cognitive Science Program, University of Waterloo, 200 University Avenue West, Waterloo, ON N2L3G1, Canada

3 Philosophy Department, Rutgers University, New Brunswick, College Avenue Campus, 106 Somerset St, 5th Floor, New Brunswick, NJ 08901, USA 


\section{Introduction}

Can we believe at will? According to the traditional view defended by Augustine, Aquinas, Pascal, James and others throughout the history of philosophy, yes we can. These thinkers all endorsed doxastic voluntarism ('doxa' = having to do with belief; hereafter voluntarism for short), which says that we have the same sort of willful control over our beliefs that we have over our actions. Descartes typifies this persuasion when he writes, "There is freedom in our will, and we often have the power to give or withhold our assent at will." In fact, Descartes thought that our ability to voluntarily control belief was "so obvious" that "it must be regarded as one of the first and most common notions that are innate in us" (Descartes 1644/ $1985, \S 39)$.

Voluntarism is not uncontroversial in the history of philosophy. Hobbes responded to Descartes by flatly claiming that belief "has nothing to do with the will" and that we simply "believe whatever is proved by valid arguments or is related in a credible manner, whether we want to or not" (Hobbes 1641, Obj. 13). Hobbes espoused doxastic involuntarism, which denies that we have the same sort of willful control over our beliefs that we have over our actions. By this it is typically meant that belief cannot be "responsive to practical reasons" (Bennett 1990 , p. 90) or the result of practical reasoning that identifies belief-formation as beneficial (Feldman 2007, pp. 341 ff.). In contemporary philosophy, the tide seems to have turned against the traditional view and in favor of involuntarism, with many contemporary philosophers endorsing versions of involuntarism (e.g. Alston 1988; Bennett 1990; Buckareff 2004, 2006; Pojman 1999; Williams 1973). ${ }^{1}$

Doxastic involuntarists offer two types of arguments for their view. The first is the conceptual argument. Those who endorse the conceptual argument claim that voluntary belief is impossible "as a conceptual matter" (Scott-Kakures 1994, p. 96), or that the notion of voluntary belief is "chokingly unswallowable" (Bennett 1990, p. 90). The conceptual argument is supported by appealing to the fact that belief is truth directed or is supposed to match the world, unlike desire, which is supposed to make the world match it (O' 'haughnessy 1980; Hieronymi 2006). It is also sometimes supported by appealing to the functional role of belief in commonsense psychology, according to which belief supposedly cannot be caused in the way that intentional actions are caused (Williams 1973, in light of Scott-Kakures 1994, pp. $83 \mathrm{ff}$.), or related to intentions in the right way at any one time (Scott-Kakures 1994, pp. 93 ff.). These arguments are typically complicated and obscure, even involuntarists acknowledge that they are unpersuasive, and involuntarists admit that their case has yet to "get beyond the level of mere intuition" (Bennett 1990, p. 90). But even if involuntarists cannot provide persuasive arguments, it does not follow that their view is false. And they still tout the purported fact that "most" people who contemplate voluntary belief find it "incoherent or absurd" (Bennett 1990, p. 89; see also Hieronymi 2009). The core of conceptual involuntarism is this powerful intuition. The supporting arguments are intended help us better understand the

\footnotetext{
1 For notable exceptions see Chisholm 1964; Montmarquet 1986; Heller 2000; Winters 1979; Shah 2002; Weatherson 2008; Van Fraassen 1984; Ginet 2001; Ryan 2003; Steup 2008; Naylor 1985; Johnston 1995.
} 
intuited truth by identifying why it is true (e.g. Scott-Kakures 1994, p. 88; Hieronymi 2006, p. 49).

The second argument for involuntarism is the psychological argument (Pojman 1985; Alston 1988; Plantinga 1993; Feldman 2001, 2007). The concept of digestion does not rule out voluntary digestion. Creatures might exist that can digest, or not digest, at will. But as a matter of human physiology we simply cannot. We lack voluntary control over "gastric juices" and "cell metabolism" (Alston 1988, p. 263). Similarly, although the concept of belief does not rule out voluntary belief, as a matter of human psychology we simply cannot believe voluntarily. Involuntarists tend to provide support for the psychological argument by reporting their own strenuous, but ultimately always fruitless, efforts to believe voluntarily. For example, William Alston confesses his inability to voluntarily believe "that the United States is still a colony of Great Britain" (Alston 1988, p. 263). This inability would persist, we are told, even in the light of a $\$ 500,000,000$ inducement. The same holds true for vast swaths of beliefs, including "all normal perceptual, introspective, and memory propositions" (Alston 1988, p. 270). Alston inductively generalizes from his own inability to believe voluntarily to the conclusion that no human is "endowed with the power of taking on propositional attitudes at will" (Alston 1988, 263).

Belief is a central plank of folk psychology. Detecting when others have beliefs is a central aspect of social cognition, cooperation and communication (e.g. Baldwin and Tomasello 1998; Baron-Cohen 1995; Bartsch and Wellman 1995; Gopnik and Meltzoff 1997; Leslie 1992; Malle 2003; McCabe et al. 2000; Perner 1991; Wellman 1990). Humans would not be so surprisingly good at these tasks if they suffered from basic, glaring and unremedied errors in belief attribution (Kitcher 1984; Fodor 1987; Lahav 1992). In particular, we would not expect humans to attribute beliefs that are either straightforwardly inconsistent with the very concept of belief, or psychologically impossible for humans to form. Accordingly, if voluntary belief is a "chokingly unswallowable" conceptual impossibility, then ordinary practice will reject it and betray an implicit commitment to involuntarism (compare Scott-Kakures 1994, p. 78). By contrast, if folk psychology countenances voluntary belief, then two things follow. First, voluntary belief is a conceptual possibility and, second, it is more probable than not that voluntary belief is psychologically possible.

In this paper we present a series of experiments examining doxastic voluntarism in folk psychology. The results show that folk psychology views belief as voluntary and perhaps as the most voluntary propositional attitude. Additionally an agent's professed decision to choose or refuse to believe makes an enormous impact on whether people attribute belief to the agent, and this effect persists across extreme variations in the agent's evidence. These results provide conclusive evidence that voluntary belief is conceptually possible and thereby refute conceptual arguments for involuntarism. Moreover, given minimal assumptions about the accuracy and predictive success of folk psychological judgments, the results also make it probable that we sometimes do voluntarily believe (and suspend judgment), which undermines the psychological argument for involuntarism. 
Sections 2-8 present seven experiments on voluntarism in folk psychology. Sections 9-10 conclude the discussion by summarizing the findings, answering several objections, highlighting some implications for debates in epistemology and philosophy of religion, and proposing two hypotheses about the concept of belief which could distill a kernel of truth in involuntarism.

\subsection{Overview of the experiments}

Experiments $1 \mathrm{~A}$ and $1 \mathrm{~B}$ tested judgments about the voluntariness of ten different mental states. Belief is considered the most voluntary of them all. Experiment 2 shows that the strength of an agent's willpower significantly affects whether people agree that the person can believe voluntarily. Notably, this effect persists across very different levels of evidence possessed and does not extend to other mental states like knowledge. Experiment 3 replicates and extends this finding: agents can both choose and refuse to believe a proposition, even in spite of the evidence. Experiment 4 shows that belief is viewed as more voluntary when the relevant evidence is inferential rather than perceptual. Experiment 5 extends the basic finding to voluntary belief that is "immediate" and "actual." Experiment 6 rules out concerns that the results are due to task demand. Across all studies, we use simple and closely matched scripts based on real-world cases and examples favored by involuntarists.

\section{Experiment 1A: comparative voluntarism (politics)}

After questions were raised about Bill Clinton's relationship with Monica Lewinski, Mr. Erskine Bowles, White House Chief of Staff to President Clinton, was called to testify before a grand jury. During his testimony, Mr. Bowles told the jury, "All I can tell you is: This guy who I've worked for looked me in the eye and said he did not have ... relationships with her. And if I didn't believe him, I couldn't stay. So I believe him."

Our first study used Mr. Bowles's case as a model to probe people about ten different mental states. The goal was to assess whether they view some states as more voluntary than others. We asked about a wide range of attitudes to help contextualize our findings about the perceived voluntariness of belief. For instance, it could turn out that folk psychology views all (or no) mental states as voluntary, in which case belief would not be special. Doxastic voluntarism (involuntarism) would be a consequence of a more general view of the mental as voluntary (involuntary). By contrast, it could turn out that folk psychology views only belief as voluntary, or as the most voluntary, in which case it would be special.

\subsection{Method}

Three hundred and fifty participants were tested (aged 18-67 years, mean age $=29.7$ years; 93\% reporting English as a native language; 116 female) . Participants were recruited and tested using an online platform (Amazon Mechanical 
Turk and Qualtrics) and compensated $\$ 0.30$ for approximately 2 min of their time. Participation was restricted to United States residents. Participants were not allowed to re-take the survey. Repeat participation, within and across experiments, was prevented by screening AMT Worker IDs. These same basic recruitment and compensation procedures were used in all other experiments reported below.

Participants were randomly assigned to one of ten conditions in a betweensubjects design. Participants in each condition read a single story. The stories all featured Mrs. Platters, the chief of staff to a governor of a large state. In each story, the governor calls a meeting of his staff and tells them that his administration will support the passage of a certain bill in the legislature (House Bill H1998). He then informs them that "anyone who continues to be part of this administration" must be in a certain mental condition. The stories differed in which mental condition the governor identifies: belief, knowledge, opinion, faith, support, want, intention, doubtlessness, excitement, and fearlessness. For example, in the Believe condition it is "believe that the bill will pass," in the Know condition it is "know that the bill will pass," and in the Want condition it is "want the bill to pass." In each story, Mrs. Platters notes that she wants to continue as part of the administration and that she chooses to satisfy the governor's demand. For example, in the Believe condition, she thinks, "I want to continue as part of this administration, so I choose to believe that the bill will pass." The complete text for all stimuli is included in a supplemental file.

After reading the story, participants were asked to rate their agreement or disagreement with two statements. The first statement was that Mrs. Platters "can choose to" be in the relevant mental state. The second statement was that Mrs. Platters is now in the relevant mental state "because she made that choice." Here are the specific statements for the Believe condition:

1. Mrs. Platters can choose to believe that the bill will pass.

2. Because she made that choice, now Mrs. Platters believes that the bill will pass.

Responses were collected on a standard Likert scale, 1 ("Strongly disagree")-7 ("Strongly agree"). Each statement appeared on a new screen. Participants could not go back and change answers. The story remained at the top of the screen throughout. After testing, participants filled out a brief demographic survey.

\subsection{Results}

Preliminary analysis revealed no effects of participant age or gender on the dependent variables, so the analyses that follow collapse across those demographic variables. The same is true in all the other experiments reported in this paper.

Assignment to condition affected the extent to which participants agreed that the protagonist can choose to be in the relevant mental state, Analysis of variance (ANOVA), $\mathrm{F}(9,340)=2.114, p=.028, \eta_{\mathrm{p}}^{2}=.058 .^{2}$ Mean agreement that the

\footnotetext{
${ }^{2}$ Throughout we report effect sizes using partial Eta squared $\left(\eta_{\mathrm{p}}^{2}\right)$, which is the amount of variance in the dependent variable explained by a given independent variable. We follow Ellis (2010) for interpreting the magnitude of effect sizes. For $\eta_{\mathrm{p}}^{2}$, values greater than or equal to .14 are large, greater than or equal to .06 but less than .14 are medium, and greater than or equal to .01 but less than .06 are small.
} 
protagonist could choose was highest in the Believe condition $(M=5.58$, $\mathrm{SD}=1.12$ ). Mean agreement in the Believe condition was significantly above the neutral midpoint of $4, \mathrm{t}(32)=8.09, p<.001$, and above the mean agreement for the entire study, $\mathrm{t}(32)=3.57, p=.001$, test proportion $=4.88$. The mode response in Believe was 6 ("Agree").

Assignment to condition also affected participant agreement that the protagonist was in the relevant mental state because she chose to do so, $\mathrm{F}(9,340)=4.628$, $p<.001, \eta_{\mathrm{p}}^{2}=.109$. Mean agreement was highest in the Intend condition $(\mathrm{M}=5.74, \mathrm{SD}=1.31)$. Mean agreement in the Believe condition was nonsignificantly above the neutral midpoint of $4, \mathrm{t}(32)=1.38, p=.176$, n.s., and did not differ significantly from the mean for the entire study, $\mathrm{t}(32)=1.07, p=.295$, n.s., test proportion $=4.59$. The modes in Believe were 5 ("Somewhat agree") and 3 ("Somewhat disagree"). Results are shown in Fig. 1.

\subsection{Discussion}

We made three important findings in this study. First, participants clearly tended to agree that belief can be voluntary. Second, belief was viewed as the most voluntary of the ten mental states tested. And third, we found that participants do not indiscriminately view various attitudes as voluntary: the folk clearly view various attitudes as being more or less voluntary.

Two concerns might be raised about this study. On the one hand, perhaps the results were partly due to an implied threat that Mrs. Platters could lose her job. On the other hand, perhaps the results were partly due to participants not reading the story carefully enough to understand the details. The next study addresses both of these concerns.

\section{Experiment 1B: comparative voluntarism (UFOs)}

We ran another experiment to address the two concerns raised about Experiment 1 and to replicate the main findings by using a very different cover story. The new cover story is based on remarks by Jonathan Bennett, who says that we can "make a person temporarily believe in UFOs" by "perceptually isolating him for several days and then barraging him with propaganda," but we cannot directly entice someone to voluntarily believe in UFOs (Bennett 1990, p. 88). The story we tested in this experiment involves a seemingly outlandish belief but does not involve an implied threat to anyone.

\subsection{Method}

Participants $(\mathrm{N}=334,116$ female, aged $18-72$ years, mean age $=32.1$ years; $96 \%$ reporting English as a native language) were randomly assigned to one of ten conditions in the same between-subjects design as in Experiment 1A. Participants in each condition read a single story. The stories all featured Mrs. Platters listening to an interview on national radio about research on life satisfaction. The expert says 

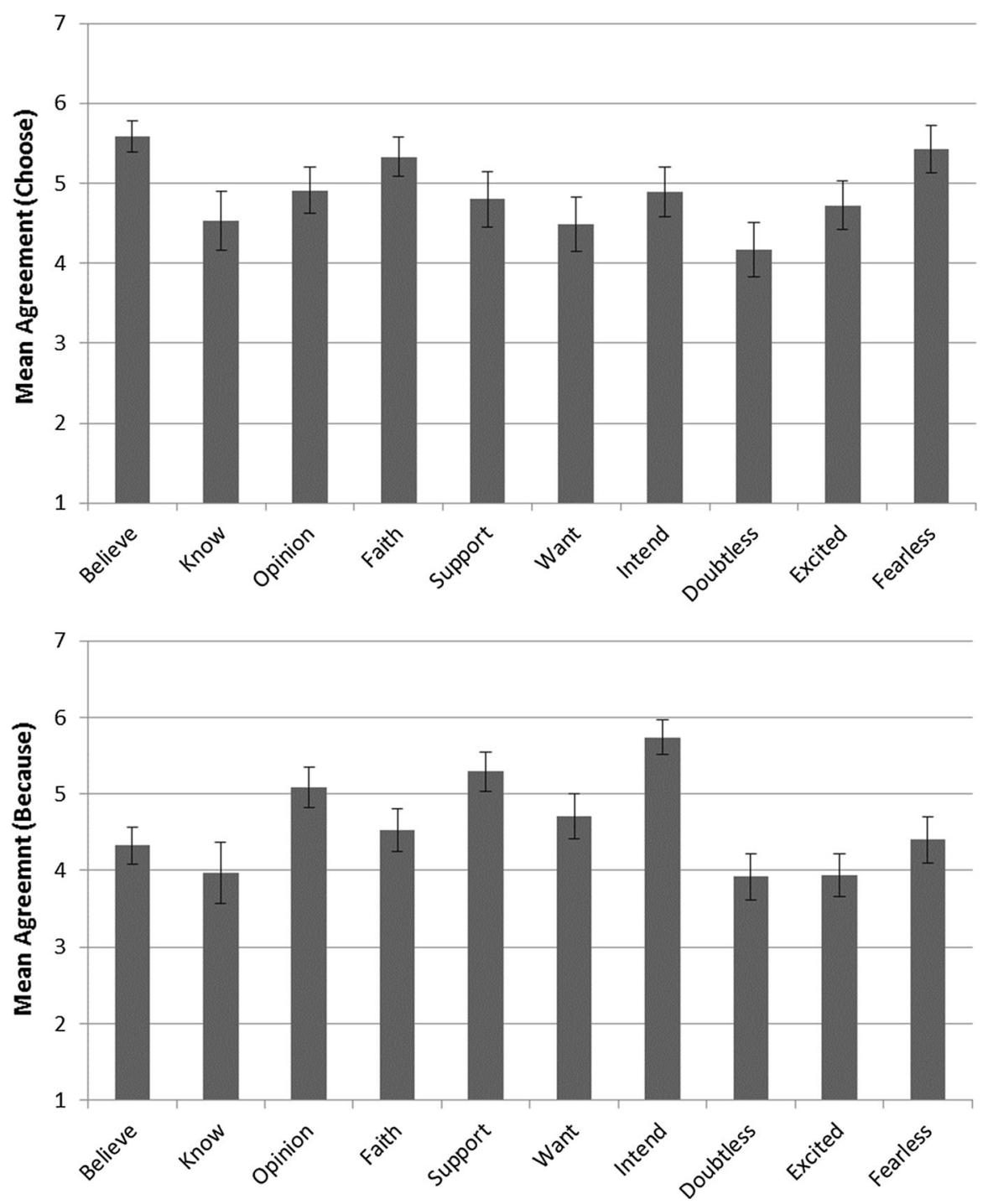

Fig. 1 Experiment 1A. Mean response to the two test statements: that the protagonist can choose to be in the mental state (top) and that the protagonist is in the mental state because of her choice (bottom). All scales ran from 1 to 7 . Error bars \pm one standard error of the mean

that the research "clearly shows that people are more satisfied with their lives when" they are in a certain mental state. The stories differed in which mental state the researcher identified. For example, in the Believe condition it is "believe that humans will discover intelligent extraterrestrials within their lifetime." In each story, Mrs. Platters then notes that she wants to be more satisfied with her life and that she chooses to be in the relevant mental state. For example, in the Believe condition, she thinks, "I want to be more satisfied with my life, so I choose to 
believe that humans will discover intelligent extraterrestrials within my lifetime." The complete text for all stimuli is included in a supplemental file.

After reading the story, participants were asked to rate their agreement or disagreement with two statements analogous to those from Experiment 1A. The first statement was that Mrs. Platters "can choose to" be in the relevant mental state. The second statement was that Mrs. Platters is now in the relevant mental state "because she made that choice." To ensure that our results were not partly due to participants reading superficially and overlooking details, we asked a comprehension question: "Mrs. Platters is a " [research scientist/chief of staff]. Response options for the comprehension question were rotated randomly. We excluded from the analysis all $(=16)$ participants who failed this question. Otherwise, the procedures for this experiment were the same as for Experiment $1 \mathrm{~A}$.

\subsection{Results}

Assignment to condition affected the extent to which participants agreed that the protagonist can choose to be in the relevant mental state, $F(9,324)=2.155$, $p=.025, \eta_{\mathrm{p}}^{2}=.056$. Mean agreement that the protagonist could choose was highest in the Believe condition $(\mathrm{M}=6.0, \mathrm{SD}=1.0)$. Mean agreement in the Believe condition was significantly above the neutral midpoint of $4, \mathrm{t}(34)=11.83$, $p<.001$, and above the mean agreement for the entire study, $\mathrm{t}(34)=4.32$, $p<.001$, test proportion $=5.27$. The mode response in Believe was 6 ("Agree") Moreover, mean agreement in the Believe condition was significantly above mean agreement in the Fearless condition $(\mathrm{M}=5.5, \mathrm{SD}=1.11)$, which was the next highest in the entire study, $\mathrm{t}(64)=1.97, p=.053, \mathrm{MD}=0.50, \eta_{\mathrm{p}}^{2}=.057$.

Assignment to condition also affected participant agreement that the protagonist was in the relevant mental state because she chose to do so, $\mathrm{F}(9,324)=5.98$, $p<.001, \eta_{\mathrm{p}}^{2}=.142$. Mean agreement was highest in the Support condition $(M=5.42, S D=1.36)$. Mean agreement in the Believe condition $(M=4.97$, $\mathrm{SD}=1.32$ ) was significantly above the neutral midpoint of $4, \mathrm{t}(34)=4.36$, $p<.001$, and was non-significantly higher than the mean for the entire study, $\mathrm{t}(34)=1.04, p=.306$, n.s., test proportion $=4.74$. The mode response in Believe was 5 ("Somewhat agree"). Results are shown in Fig. 2.

\subsection{Discussion}

The results replicated the three main findings from Experiment 1A. First, participants clearly tended to agree that belief can be voluntary. Second, belief was viewed as the most voluntary of the ten mental states tested. And third, people do not indiscriminately view various attitudes as voluntary: they distinguish between a range of attitudes, holding that some are more or less voluntary than others. These results seriously undermine the view that voluntary belief is conceptually impossible. For if it were conceptually impossible, we would not expect such clear and widespread agreement that belief can be voluntary.

Both studies thus far have two limitations. First, although we claim that participants view belief as voluntary, we did not actually intervene on the 

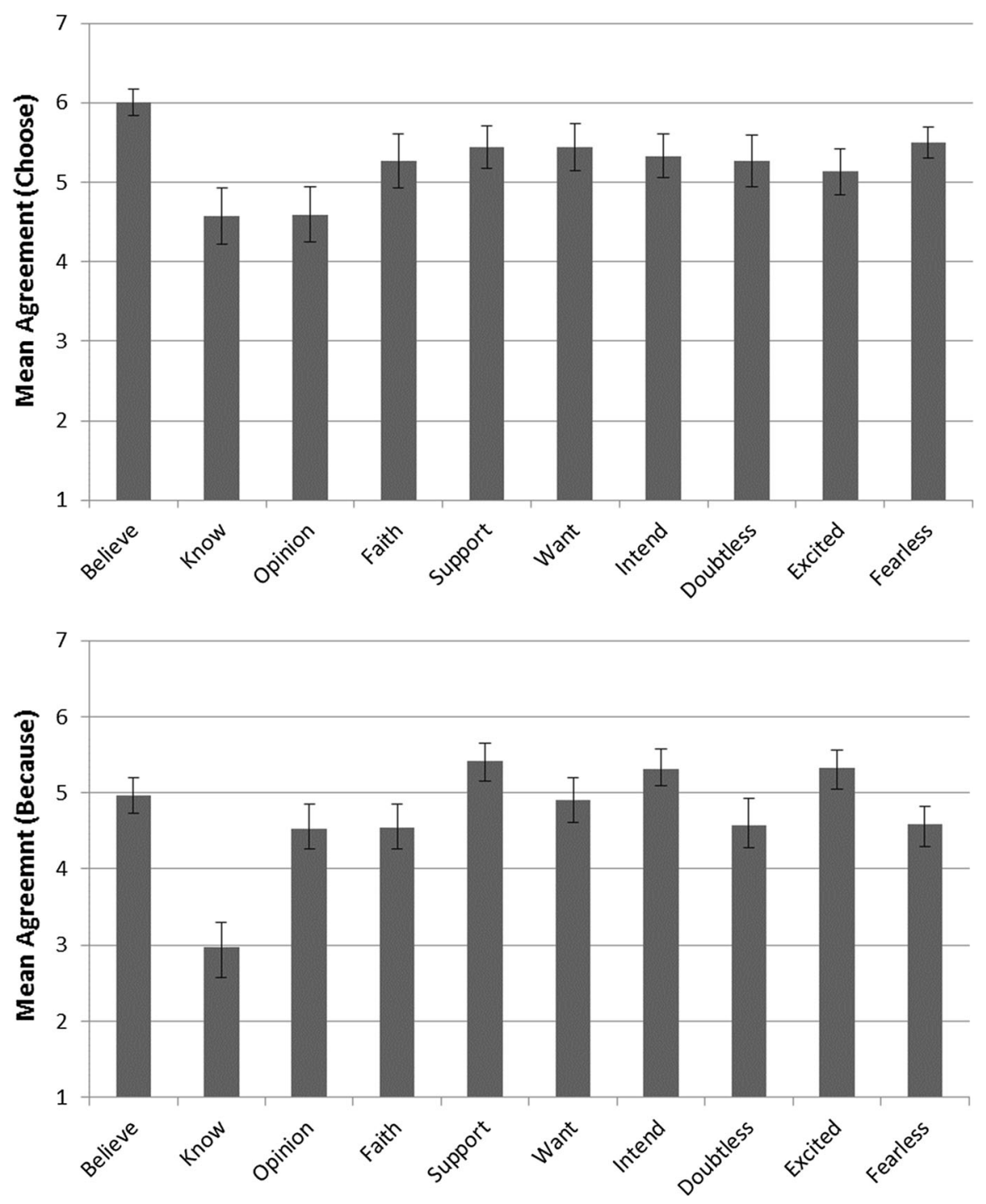

Fig. 2 Experiment 1B. Mean response to the two test statements: that the protagonist can choose to be in the mental state (top) and that the protagonist is in the mental state because of her choice (bottom). All scales ran from 1 to 7 . Error bars \pm one standard error of the mean

protagonist's willfulness (see Scheines 1997 for a discussion of interventions). That is, we did not manipulate whether the protagonist was more or less willful. Thus we have not shown that participant's view the protagonist's will as responsible for the belief. The results from the "because" statement are suggestive, but they are no substitute for a direct intervention. Second, we did not manipulate a key factor that many philosophers think is relevant to assessing voluntarism's plausibility, namely, 
evidence (James 1896/1948; Alston 1988; Ginet 2001). The next experiment addresses both of these limitations.

Before moving on, we would like to address one question, likely to occur to some readers, about the results thus far. Why were participants so willing to agree that knowledge was voluntary? Our explanation is that knowledge requires belief, a requirement that is deeply reflected in folk psychology (Rose and Schaffer 2013; Buckwalter et al. 2015). On a reasonable and natural way of interpreting the cases, in order to gain knowledge, the only thing left for the agent to do is to form the belief. All of the other intuitive conditions on knowledge are already in place. So there is a sense in which the agent chooses to know, namely, by choosing to believe. Viewing the case this way could have led many participants to attribute voluntary knowledge.

\section{Experiment 2: manipulating willfulness and evidence}

In this study we manipulated the agent's evidence by varying whether the probability of the outcome was described as low or high. We manipulated the agent's willfulness by varying whether she was weak or strong willed. Instead of asking about a wide range or attitudes, as we did in experiments $1 \mathrm{~A}$ and $1 \mathrm{~B}$, we narrowed our focus to comparing judgments about belief and knowledge.

\subsection{Method}

Participants $(\mathrm{N}=273,108$ female, aged $18-73$ years, mean age $=29.6$ years; $97 \%$ reporting English as a native language $)^{3}$ were randomly assigned to one of eight conditions in a 2 (Probability: Lower/Higher) $\times 2$ (State: Believe/Know) $\times 2$ (Will: Weak/Strong) between-subjects design. Participants in each condition read a single story. The basic storyline again featured Mrs. Platters and the governor. The governor informs his staff that his administration will support the passage of a certain bill in the legislature. The Probability factor manipulates the percentage of legislators who are currently in favor of voting for the bill: $30 \%$ in the Lower probability conditions compared to $70 \%$ in the Higher probability conditions. The State factor manipulates which mental state the governor requires from anyone interested in being on his special legislative task force: that they either believe or know that the bill will pass. The Will factor manipulates how willful Mrs. Platters is: she is "extremely weak willed" in Weak conditions and "extremely strong willed" in Strong conditions. Here is the story, with variations in brackets and separated by a slash:

The governor of a large state calls a meeting of his staff and tells them, "I've decided that my administration will fully support the passage of House Bill H1998. As of right now, [30 / 70]\% of House members will vote for the bill. Despite those numbers, we cannot [give up / relax] now. So, from this day

\footnotetext{
${ }^{3}$ We excluded data from 8 participants who failed a comprehension question.
} 
forth, anyone who wants to be on my legislative task force must [believe / know] that the bill will pass." " After the meeting, the governor's chief of staff, Mrs. Platters, thinks to herself, "I want to be on the legislative task force, so I choose to [believe / know] that the bill will pass." " Mrs. Platters has always been extremely [weak / strong] willed. For example, she loves cupcakes and cookies, but [although / because] she wants to stop eating them for health reasons, she simply [can't overcome / overcomes] the temptation.

Participants then responded to two test statements analogous to those presented in Experiments $1 \mathrm{~A}$ and $1 \mathrm{~B}$ :

1. Mrs. Platters can choose to believe/know that the bill will pass.

2. Because she made that choice, now Mrs. Platters believes/knows that the bill will pass.

Responses were collected on the same standard Likert scale, 1 ("Strongly disagree")-7 ("Strongly agree"). Participants then answered the same comprehension question as in Experiment 1B.

\subsection{Results}

We will first analyze the results for the first statement about whether the protagonist can choose to be in the relevant mental state. There was a main effect of Probability, with agreement higher in Higher probability conditions, $F(1,265)=4.254$, $p=.04, \eta_{\mathrm{p}}^{2}=.016$. There was a main effect of State, with agreement higher in Believe conditions, $\mathrm{F}(1,265)=12.49, p<.001, \eta_{\mathrm{p}}^{2}=.045$. There was no main effect of Will, $\mathrm{F}(1,265)=1.67, p=.194$, n.s. Crucially, the main effect of State was qualified by a two-way interaction between State and Will, whereby changing the will from Weak to Strong increased agreement in Believe conditions but not in Know conditions, $\mathrm{F}(1,265)=3.627, p=.058, \eta_{\mathrm{p}}^{2}=.014$. No other interaction was statistically significant.

To better understand the results, we conducted a series of planned comparisons. First, pairwise comparisons revealed that in Lower probability Believe conditions, agreement was higher when the will was Strong $(\mathrm{M}=5.51, \mathrm{SD}=1.58)$ than when it was Weak $(\mathrm{M}=4.77, \mathrm{SD}=1.59), \mathrm{t}(68)=-1.96, p=.054, \mathrm{MD}=-0.74$, $\eta^{2}=.053$, and in Higher probability Believes conditions, agreement was trending higher when the will was Strong $(\mathrm{M}=5.62, \mathrm{SD}=1.37)$ than when it was Weak $(\mathrm{M}=5.06, \mathrm{SD}=1.51), \mathrm{t}(67)=-1.61, p=.111, \mathrm{MD}=0.56, \eta^{2}=.038$. By contrast, in Lower probability Know conditions, agreement was non-significantly higher when the will was Weak $(\mathrm{M}=4.23, \mathrm{SD}=1.68)$ than when it was Strong $(\mathrm{M}=4.17, \mathrm{SD}=2.0)$, and the same was true in Higher probability Know conditions $(\mathrm{M}=4.94 / 4.75, \quad \mathrm{SD}=1.81 / 1.80)$. Second, pairwise comparisons revealed that agreement was significantly higher for Believe than for Know in Lower probability Strong will conditions, $\mathrm{M}=5.51 / 4.17, \quad \mathrm{SD}=1.58 / 2.01$, $\mathrm{t}(64.43)=3.11, p=.003, \mathrm{MD}=1.34, \eta^{2}=.126$, and in Higher probability

\footnotetext{
${ }^{4}$ Indicates a paragraph break on the participant's screen.
} 
Strong will conditions, $\mathrm{M}=5.62 / 4.75, \mathrm{SD}=1.37 / 1.79, \mathrm{t}(57.95)=2.20, p=.032$, $\mathrm{MD}=0.87, \eta^{2}=.066$. Agreement was non-significantly higher for Believe in Lower probability Weak will conditions, $\mathrm{M}=4.77 / 4.23, \mathrm{SD}=1.59 / 1.68$, $\mathrm{t}(68)=68, p=.170$, n.s., and in Higher probability Weak will conditions, $\mathrm{M}=5.06 / 4.94, \mathrm{SD}=1.51 / 1.81, p=.770$, n.s. Third, one-sample t-tests revealed that mean agreement was significantly above the midpoint $(=4)$ in all four individual Believe conditions, all $p s \leq .007$. By contrast, it was above the midpoint for Know conditions when evidence was Higher, $p \mathrm{~s} \leq .025$, but not when it was Lower, $p s \geq .427$.

Next we will analyze the results for the second statement about whether the protagonist is in the relevant mental state because she chose to be. There was a main effect of State, with agreement higher in Believe conditions $(\mathrm{M}=5.09, \mathrm{SD}=1.56)$ than in Know conditions $(\mathrm{M}=3.98, \mathrm{SD}=1.83), \mathrm{F}(1,265)=28.74, \eta_{\mathrm{p}}^{2}=.098$. There was a trending main effect of Probability, with agreement higher in Higher $(\mathrm{M}=4.73, \mathrm{SD}=1.77)$ than in Lower $(\mathrm{M}=4.36, \mathrm{SD}=1.78)$ probability conditions.

We again conducted a series of planned comparisons. First, pairwise comparisons revealed that in Lower probability Believes conditions, agreement was trending higher when the will was Strong $(\mathrm{M}=5.29, \mathrm{SD}=1.54)$ than when it was Weak $(\mathrm{M}=4.63, \quad \mathrm{SD}=1.65), \mathrm{t}(68)=-1.72, \quad p=.09, \quad \mathrm{MD}=-0.66, \quad \eta_{\mathrm{p}}^{2}=.042$, whereas in Higher probability Believes conditions, agreement was non-significantly higher when the will was Strong $(\mathrm{M}=5.35, \mathrm{SD}=1.56)$ than when it was Weak $(\mathrm{M}=5.09, \mathrm{SD}=1.46), p=.465$, n.s. By contrast, in Lower probability Knows conditions, agreement was non-significantly higher when the will was Weak $(\mathrm{M}=3.80, \mathrm{SD}=1.64)$ than when it was Strong $(\mathrm{M}=3.74, \mathrm{SD}=1.87)$, $p=.892$, n.s., and the same was true in Higher probability Know conditions $(\mathrm{M}=4.31 / 4.09, \mathrm{SD}=1.96 / 1.86), p=.648$, n.s. Second, pairwise comparisons revealed that agreement was significantly higher for Believe than for Know in Lower probability Weak will conditions, $\mathrm{M}=4.63 / 3.80, \quad \mathrm{SD}=1.65 / 1.64$, $\mathrm{t}(68)=2.11, p=.039, \mathrm{MD}=0.83, \eta_{\mathrm{p}}^{2}=.061$, in Lower probability Strong will conditions, $\mathrm{M}=5.29 / 3.74, \mathrm{SD}=1.55 / 1.87, \mathrm{t}(68)=3.77, p<.001, \mathrm{MD}=1.55$, $\eta_{\mathrm{p}}^{2}=.173$, and in Higher probability Strong will conditions, $\mathrm{M}=5.35 / 4.09$, $\mathrm{SD}=1.56 / 1.86, \mathrm{t}(64)=3.0, p=.004, \mathrm{MD}=1.26, \eta_{\mathrm{p}}^{2}=.123$. Agreement was trending higher for Believe than for Know in Higher probability Weak will conditions, $\quad \mathrm{M}=5.09 / 4.31, \quad \mathrm{SD}=1.46 / 1.96, \quad \mathrm{t}(57.14)=1.82, \quad p=.074$, $\mathrm{MD}=0.78, \eta_{\mathrm{p}}^{2}=.049$. Third, one-sample t-tests revealed that mean agreement was significantly above the neutral midpoint in all four individual Believe conditions, all $p \mathrm{~s} \leq .030$. By contrast, in no Know condition did it differ from the midpoint, $p s \geq .374$. Results are shown in Fig. 3 .

\subsection{Discussion}

Three important findings emerge from this experiment. First, belief is clearly viewed as voluntary, whereas knowledge is not. This replicates a main finding from Experiments $1 \mathrm{~A}$ and 1B. Second, manipulating a protagonist's willpower significantly affects whether people view her as effectively able to choose to believe, but 

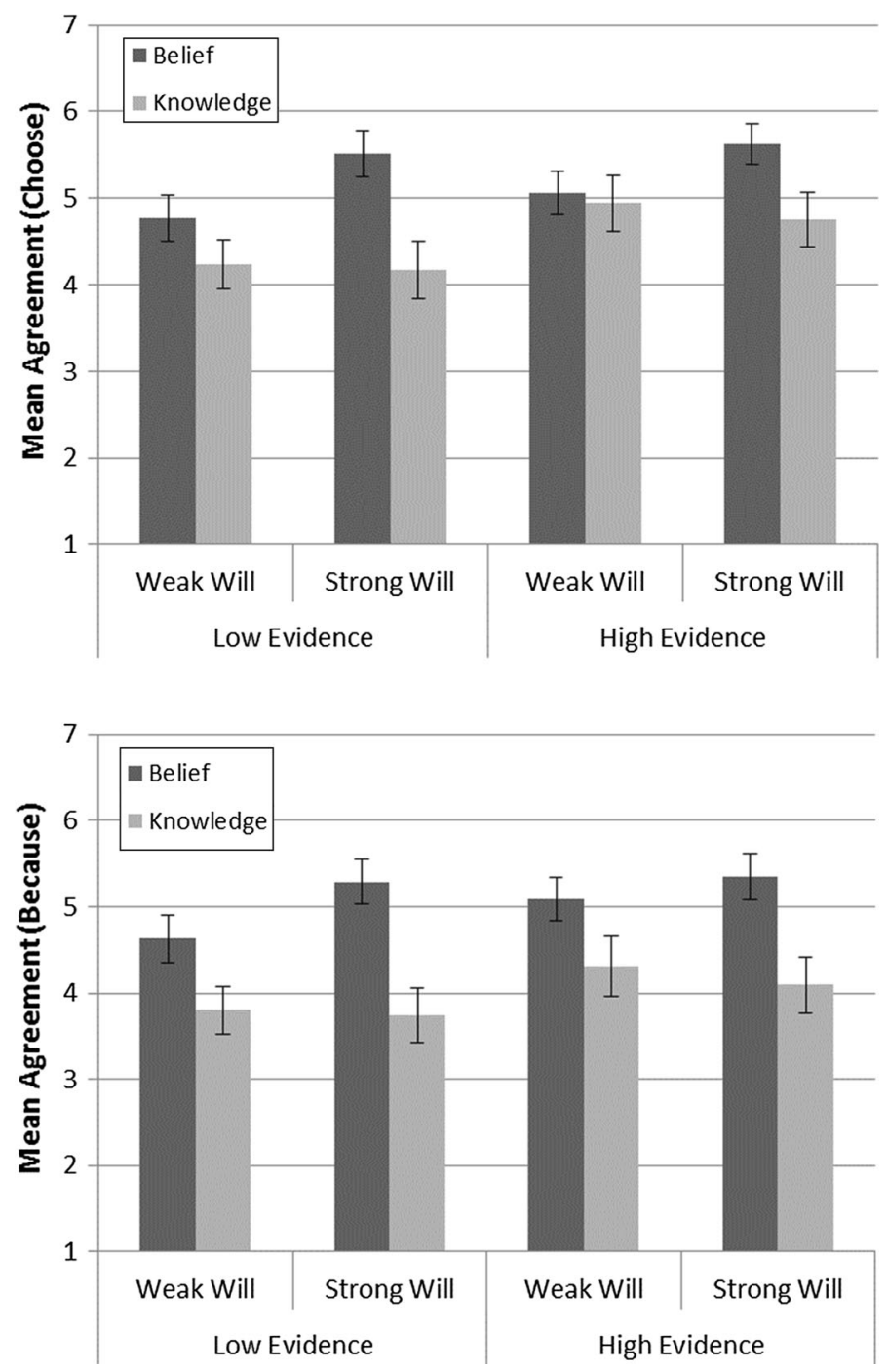

Fig. 3 Experiment 2. Mean response to the two test statements: that the protagonist can choose to be in the mental state (top), and that the protagonist is in the mental state because of her choice (bottom) for knowledge and belief. All scales ran from 1 to 7. Error bars \pm one standard error of the mean

the same is not true for choosing to know. This is very important because it shows not only that are people willing to classify belief as voluntary but also that their belief assessments are sensitive to interventions on the protagonist's willfulness. Third, the perceived effect of greater willpower is present when the quality of evidence is higher and when it is lower. This is suggestive because some philosophers have speculated that the scope of doxastic voluntarism is limited to cases where the evidence is weak or ambiguous (e.g. Alston 1988, pp. 264, 270). But we did not observe a significant difference between cases where the evidence 
suggested that a proposition was probably true and cases where it was probably false. The next study pursues this last point in greater detail.

\section{Experiment 3: manipulating choice and evidence}

Philosophers have pointed out that if doxastic voluntarism were true, then people would be able to not only choose to believe but also refuse to believe (Alston 1988, p. 261; Naylor 1985, p. 430). Doxastic involuntarists have also claimed that voluntarism's plausibility derives from cases involving weak or ambiguous evidence (Alston 1988, p. 270; compare Feldman 2007, p. 342). And many of the most widely discussed examples offered by voluntarists do seem to be cases that involve beliefs formed inferentially or indirectly on the basis of inconclusive evidence (e.g. Ginet 2001, p. 64). Lastly, the experiments up till now have featured stories where other agents offer inducements to believe. This experiment explores the issues raised by both points above and expands the results to cases that do not involve external rewards offered by other agents.

\subsection{Method}

Participants $(\mathrm{N}=213 ; 80$ female, aged $18-69$ years, mean age $=31.3$ years; $91 \%$ reporting English as a native language) were randomly assigned to one of six conditions in a 3 (Probability: 5/50/95\%) × 2 (Option: Refuse/Choose) betweensubjects design. Participants in each condition read a single story. The basic storyline featured Malcolm, who planned a graduation party for tomorrow at the local park. Malcolm checks tomorrow's weather forecast. The Probability factor manipulates the chance of rain reported on the forecast: 5, 50, or 95\%. The Option factor manipulates whether Malcolm is either optimistic, in which case he refuses to believe that it will rain tomorrow, or pessimistic, in which case he chooses to believe that it will rain. Here is the story, with variations in brackets and separated by a slash:

Malcolm planned a graduation party for tomorrow at the local park. He checks the weather forecast and sees that there is a [5/50/95]\% chance that it will rain tomorrow. Malcolm has a tendency to be very [optimistic / pessimistic]. He thinks to himself, "I [refuse / choose] to believe that it's going to rain tomorrow."

Participants then responded to a test statement: "Malcolm believes that it will rain tomorrow." Responses were collected on the same standard Likert scale, 1 ("Strongly disagree")-7 ("Strongly agree").

Note that this time the test statement does not say that the agent can choose to believe that it will rain. Instead, it directly attributes the belief to Malcolm. 


\subsection{Results}

There was a medium-sized main effect of Probability on belief attribution, F(2, $207)=7.219, p<.001, \eta_{\mathrm{p}}^{2}=.065$; there was a very large main effect of Option, $\mathrm{F}(1,207)=374.25, p<.001, \eta_{\mathrm{p}}^{2}=.644$, with attribution much higher in Choose than Refuse conditions; and there was no interaction between Probability and Option, $p=.381$, n.s. One sample t-tests revealed that mean attribution was significantly above the neutral midpoint $(=4)$ in each of the three Choose conditions but significantly below the midpoint in each of the three Refuse conditions, all $p$ s $<.001$. It is particularly noteworthy that mean attribution in the $5 \%$ Choose condition $(\mathrm{M}=5.63, \mathrm{SD}=1.63)$ was significantly higher than in the $95 \%$ Refuse condition $(\mathrm{M}=2.54, \mathrm{SD}=1.72), \mathrm{t}(68)=-7.705, \quad p<.001, \mathrm{MD}=-3.08$, $\eta_{\mathrm{p}}^{2}=.466$. By contrast, the difference between mean attribution in $5 \%$ Choose and $95 \%$ Choose $(\mathrm{M}=6.25, \mathrm{SD}=.81)$ was statistically significant but small, $\mathrm{t}(49.41)=-2.03, p=.048, \mathrm{MD}=-0.62, \eta_{\mathrm{p}}^{2}=.056$. Results are shown in Fig. 4.

\subsection{Discussion}

Two important findings emerge from this experiment. First, people's willingness to attribute belief is strongly influenced by a protagonist's professed choice to believe or refuse to believe a proposition. When the protagonist said that he chooses to believe, people overwhelmingly attributed the belief to him. When the protagonist said that he refuses to believe, people overwhelmingly denied the belief to him. Second, this pattern was surprisingly resistant to the evidence available to the protagonist, replicating and extending one main finding from Experiment 2, whereby there was only a trending main effect of probability. In the present experiment, it made only a small difference to belief attribution that the proposition was only $5 \%$ likely to be true rather than $95 \%$. The added ninety percent probability

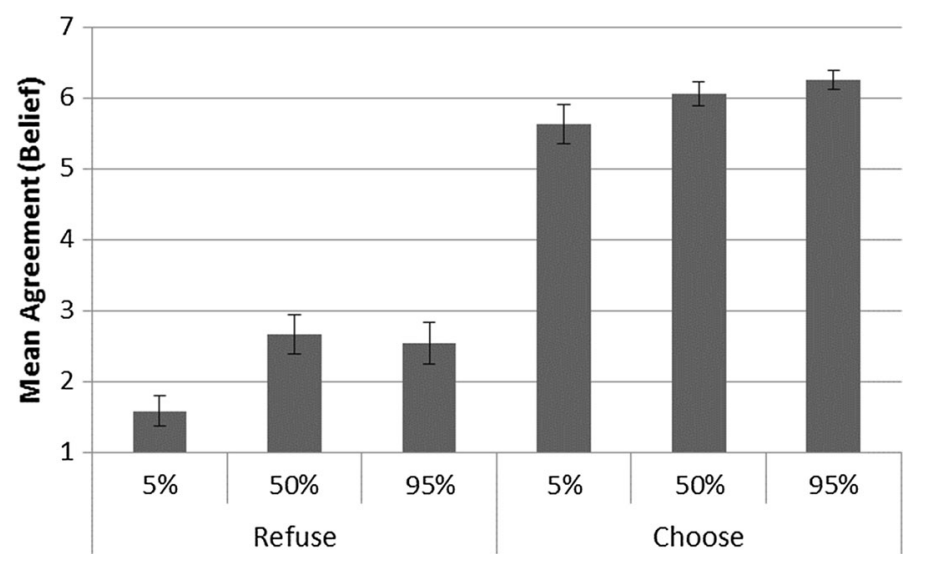

Fig. 4 Experiment 3. Mean belief attribution to a protagonist who professed to either choose or refuse to believe a proposition that is either 5, 50, or 95\% probable. All scales ran from 1 to 7 . Error bars \pm one standard error of the mean 
made people only slightly more inclined to attribute belief based on a professed choice to believe. Similarly, that same ninety percent increase made people only slightly less inclined to deny belief based on a professed refusal to believe. In short, belief and non-belief were widely viewed as voluntary despite the evidence.

\section{Experiment 4: manipulating choice and evidential source}

One limitation of the previous experiment is that it focused only on inferential beliefs and treated evidence as a function of probability. However, some experimental work suggests that the source of evidence is a qualitative factor that can significantly affect some mental state attributions (O'Neill et al. 1992; Wang et al. 2014; Turri 2015a, b). Some voluntarists have conceded that perceptual beliefs are involuntary (e.g., Weatherson 2008). And involuntarists have repeatedly singled out perceptual beliefs-in particular, perceptual beliefs about precipitation-as paradigm examples of beliefs that resist voluntary control (e.g. Plantinga 1993). Writes Alston,

When I look out my window and see rain falling, water dripping off the leaves of trees, and cars passing by, I ... [do not] have immediate control over whether I accept those propositions. ... I form the beliefs that rain is falling, etc. willy-nilly. There is no way I can inhibit these beliefs. (Alston 1988, p. 270).

\section{Writes Richard Feldman,}

About half the time it snows here in Rochester during the winter, and today is a typical winter day. I am unsure whether it is snowing at the moment. I cannot, just by thinking about it, get myself to believe that it is snowing now. Nor can I get myself to believe that it is not snowing. (Feldman 2007, p. 341)

The present study investigates the effect of evidential source on people's judgments about whether one can choose or refuse to belief.

\subsection{Method}

Participants $(\mathrm{N}=128,60$ female, aged $18-70$ years, mean age $=31.4$ years; $94 \%$ reporting English as a native language) were randomly assigned to one of four conditions in 2 (Source: Perceive/Infer) $\times 2$ (Option: Refuse/Choose) betweensubjects design. Participants in each condition read a single story. The basic storyline again featured Malcolm, who planned a graduation party for today at the local park. The Source factor manipulates where Malcolm gets his evidence. In the Perceive conditions, perception is the source of Malcolm's evidence: he looks out the window and sees what appears to be rain. In the Infer condition, a reported statistic is the source of Malcolm's evidence: he checks the forecast and learns that rain showers are currently likely in the area. The Option factor manipulates whether Malcolm is either optimistic, in which case he refuses to believe that it is raining, or 
pessimistic, in which case he chooses to believe that is raining. Here is the story, with variations in brackets and separated by a slash:

Malcolm planned a graduation party for today at the local park. Before heading out to the party, he [looks toward the window and sees what appear to be water drops starting to hit the window sill / checks the weather report and it says that rain showers are likely in the area right now]. Malcolm has a tendency to be very [optimistic / pessimistic]. He thinks to himself, "I [refuse / choose] to believe that it's raining."

Participants then rated their agreement with a belief attribution: "Malcolm believes that it's raining." Responses were collected on the same standard Likert scale, 1 ("Strongly disagree")-7 ("Strongly agree").

\subsection{Results}

There was a medium-sized main effect of Source on belief attribution, F(1, $124)=12.41, p<.001, \eta_{\mathrm{p}}^{2}=.091$, with attribution higher in Perceive conditions. There was a very large main effect of Option, $\mathrm{F}(1,124)=90.80, p<.001$, $\eta_{\mathrm{p}}^{2}=.644$, with attribution much higher in Choose than Refuse conditions. There was a trending interaction between Source and Option, whereby the switch from Choose to Refuse depressed attribution for Infer more than Perceive, $\mathrm{F}(1$, $124)=2.671, p=.105, \eta_{p}^{2}=.021$. Pairwise comparisons revealed that belief attribution was significantly higher in Refuse Perceive $(M=3.94, \mathrm{SD}=2.22)$ than in Refuse Infer $(\mathrm{M}=2.48, \mathrm{SD}=1.52), \mathrm{t}(52.73)=3.03, p=.004, \mathrm{MD}=1.45$, $\eta_{\mathrm{p}}^{2}=.129$. By contrast, belief attribution was only marginally higher in Choose Perceive $(M=6.16, S D=.99)$ than in Choose Infer $(M=5.63, S D=1.41)$, $\mathrm{t}(55.54)=1.75, p=.086, \mathrm{MD}=0.531, \eta_{\mathrm{p}}^{2}=.047$. One-sample t-tests revealed that belief attribution was significantly above midpoint in Choose Perceive and

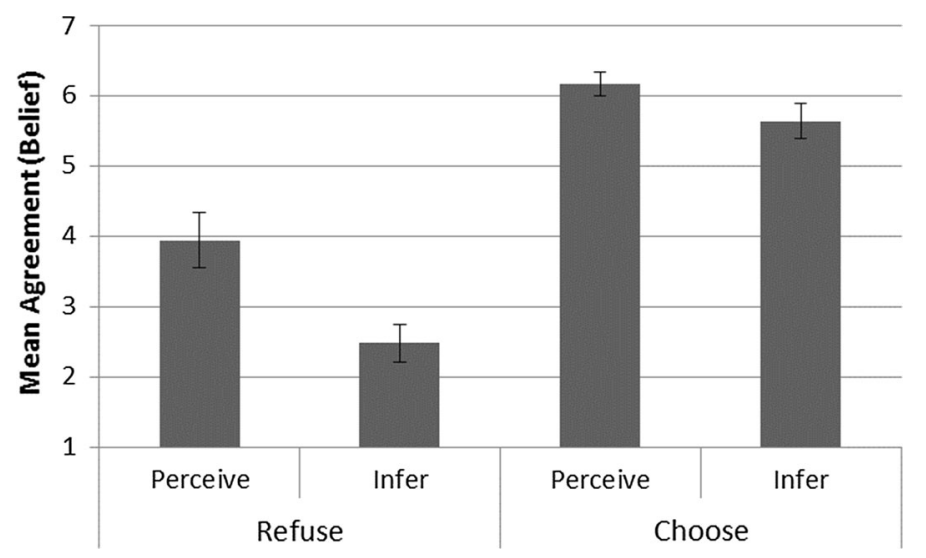

Fig. 5 Experiment 4. Mean belief attribution to a protagonist who professed to either choose or refuse to believe a proposition based on perception or inference. All scales ran from 1 to 7 . Error bars \pm one standard error of the mean 
Choose Infer, $p$ s $<.001$, significantly below midpoint in Refuse Infer, $p<.001$, and no different from midpoint in Refuse Perceive, $p=.873$. Results are shown in Fig. 5.

\subsection{Discussion}

Two important findings emerge from this experiment. First, we again replicated the result that belief is very widely viewed as voluntary. Once again, people attributed belief to someone who professed to choose to believe, and they denied belief to someone who professed to refuse to believe. Second, as suggested by the examples used by many doxastic involuntarists, belief is viewed as less voluntary when the relevant evidence is perceptual rather than inferential. In particular, whereas people think that one can refuse to believe based on inferential evidence, they are overall ambivalent on whether one can refuse to believe based on perceptual evidence. By contrast, people clearly think that one can choose to believe based on both inferential evidence and perceptual evidence. But our findings differ from the involuntarists' suggestion in at least one respect: whereas involuntarists claim that perceptual beliefs are obviously not subject to voluntary control, our data suggest that it is at best unclear whether perceptual beliefs are subject to voluntary control. This is not what we would expect if voluntary perceptual belief, or non-belief, was conceptually impossible.

\section{Experiment 5: immediate belief and actual belief}

Two concerns might be raised about our earlier results. First, it might be objected that involuntarists ultimately only care whether belief is immediately voluntary, whereas in our earlier experiments perhaps people attributed belief that is voluntary only indirectly. That is, perhaps people think that belief can be voluntarily acquired as the result of a protracted process of selective attention or memory, but they do not think that one can choose to immediately acquire a belief. Second, it might be suggested that people ascribe voluntary "belief" in name only, perhaps in deference to the agent's expressed intentions, even though they do not think that the agent actually believes the proposition in question. We ran another experiment to test these two concerns. We asked participants whether an agent who chooses to believe forms the belief "immediately," and we asked whether the agent "actually" holds the belief. As a point of comparison, we also asked people to consider an agent who claims that he will do something impossible.

\subsection{Method}

Participants $(\mathrm{N}=104,43$ female, aged $18-59$ years, mean age $=30$ years; $96 \%$ reporting English as a native language) were randomly assigned to one of three conditions (Immediate Belief, Actual Belief, Actual Action) in a between-subjects design. Participants in each condition read a single story. The basic storyline featured Eric, who hears the governor give a stirring speech. In the penultimate line 
of her speech, the governor says, "We need to have the right attitude - the attitude that we can do the impossible." The stories for the three conditions differ in how the governor ends her speech, what Eric thinks in response, and the specific wording of the test statement. In the Immediate Belief condition, the governor urges people to, "immediately and without delay, believe that we can do the impossible." In the Actual Belief and Actual Action conditions, she urges people to "believe that we can do the impossible." Here is the story, with manipulations in brackets and separated by a slash (Immediate Belief / Actual Belief / Actual Action):

Eric attended a political rally today at a local community college. The governor gave a speech, in which she said, "We need to fix the serious problems facing our state. To do that, we need to have the right attitude - the attitude that we can do the impossible. We must [, immediately and without delay, believe that we can / believe that we can / believe that we can] do the impossible." The speech deeply impresses Eric, who immediately thinks to himself, ["I choose, right now, to believe that we can do the impossible." / "I choose to believe that we can do the impossible." / "I will, right now, do something that is impossible."]

Participants then rated their agreement with a single test statement: "Upon hearing the governor's speech, Eric [immediately believes that he can do / actually believes that he can do / actually does] something impossible." Responses were collected on the same standard Likert scale from earlier experiments, 1 ("Strongly disagree")-7 ("Strongly agree").

\subsection{Results}

There was a very large main effect of condition on agreement with the test statement, $\mathrm{F}(2,101)=31.14, p<.001, \eta_{\mathrm{p}}^{2}=.381$. Pairwise comparisons with independent samples t-tests revealed that mean agreement was higher in Immediate Belief $(\mathrm{M}=5.74, \mathrm{SD}=1.31)$ than in Actual Action $(\mathrm{M}=3.11, \mathrm{SD}=1.73)$, $\mathrm{t}(63.30)=7.11, p<.001, \eta_{\mathrm{p}}^{2}=.428$; it was higher in Actual Belief $(\mathrm{M}=5.29$, $\mathrm{SD}=1.36$ ) than in Actual Action, $\mathrm{t}(68)=5.84, p<.001, \eta_{\mathrm{p}}^{2}=.334$; but it did not differ significantly between Immediate Belief and Actual Belief, $t(67)=1.40$, $p=.167$, n.s. One-sample $t$ tests revealed that mean agreement was significantly above the neutral midpoint $(=4)$ in Immediate Belief, $\mathrm{t}(33)=7.73, p<.001$, $\mathrm{MD}=1.74,95 \%$ CI $1.28-2.19, \mathrm{~d}=1.32$, significantly above the midpoint in Actual Belief, $\mathrm{t}(34)=5.58, p<.001, \mathrm{MD}=1.3,95 \%$ CI $0.82-1.75, \mathrm{~d}=0.95$, but significantly below the midpoint in Actual Action, $\mathrm{t}(34)=-3.03, p<.005$, $\mathrm{MD}=-0.89,95 \% \mathrm{CI}-1.48$ to $-0.29, \mathrm{~d}=0.51$. Results are shown in Fig. 6 .

\subsection{Discussion}

Two important findings emerge from this experiment. On the one hand, people readily agreed that someone who professed to choose to believe forms the belief "immediately." On the other hand, people readily agreed that someone who professed to choose to believe "actually" forms the belief. People view voluntary 


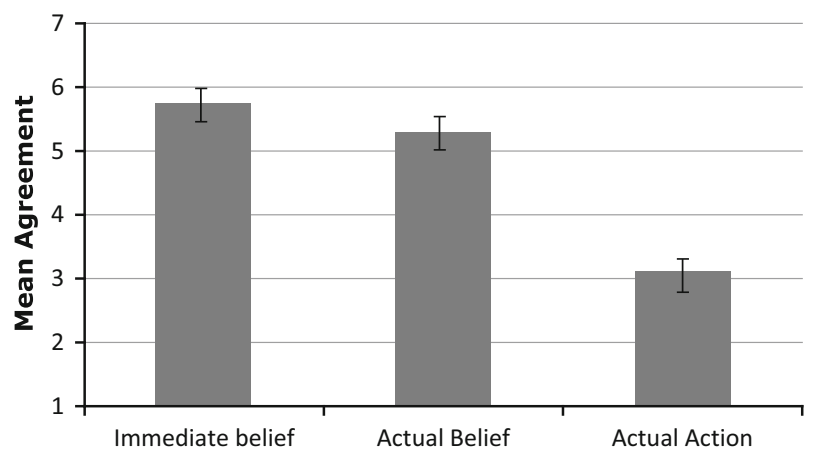

Fig. 6 Experiment 5. Mean agreement that the protagonist immediately forms a belief, actually forms a belief, or actually performs an action. All scales ran from 1 to 7 . Error bars \pm one standard error of the mean

belief, both immediate and actual, very differently from the performance of impossible tasks. In particular, people disagree that an agent can do something impossible, whereas they agree that an agent can choose to actually and immediately form a belief. This addresses both concerns raised about the interpretation of earlier results, and it further strengthens the already impressive evidence that voluntary belief is conceptually possible.

\section{Experiment 6: belief, acceptance, and imagining}

Another concern might be raised about our earlier results. ${ }^{5}$ The concern is that people attributed belief due to task demand, which could take either of two forms. On the one hand, perhaps people attributed belief simply because the agent used the word "believe." In the earlier studies, if the agent had not used that specific word, then people might not have attributed "belief." On the other hand, perhaps people were not given sufficient flexibility in their response options. In the philosophical literature on belief, it is popular to distinguish between belief and "belief-like attitudes" (Frankish 2007, p. 536), such as "acceptance" (Cohen 1992), and to claim that although belief is involuntary, some belief-like attitudes are voluntary. In the earlier studies, perhaps people recognized that the agent formed a belief-like attitude and attributed "belief" not because they genuinely thought that the agent formed a voluntary belief, but rather because attributing "belief" was the best option available to them. If "acceptance" had been an option, then people might not have attributed "belief." Also in the philosophical literature on belief, some theorists have argued that some attitudes are more like imaginings than beliefs (e.g. Egan 2009). Again, perhaps people recognized that the agent formed a belief-like attitude and attributed "belief" as a way to convey that fact. If "imagines" had been an option, then people might not have attributed "belief." We ran one final

\footnotetext{
5 Thanks to an anonymous referee for proposing the concerns.
} 
experiment to test these possibilities. We asked participants to "check all that apply" from a list of attitudes, including "believes," "accepts," and "imagines."

\subsection{Method}

Participants $(\mathrm{N}=121,47$ female, aged 19-68 years, mean age $=34$ years; $95 \%$ reporting English as a native language) were randomly assigned to one of two conditions (Believe, Accept) in a between-subjects design. Participants in the Believe condition of this experiment read the story for the Immediate Belief condition of Experiment 5. Participants in the Accept condition of this experiment read a very similar story, with the following differences: the governor urges people to "immediately and without delay, accept that we can do the impossible," and Eric thinks to himself, "I choose, right now, to accept that we can do the impossible" (the switch is from "believe" to "accept"; emphases added here for clarity; participants did not see an italicized word). Participants were then instructed, "Please check all the options that accurately describe Eric," followed by an open sentence, "Upon hearing the governor', speech, Malcolm immediately ___ that he can do something impossible." Below the open sentence were six options, displayed vertically in randomized order: believes, accepts, imagines, knows, denies, rejects.

The purpose of including the six options for mental state attribution was to give people flexibility to attribute a mental state other than belief. More specifically, we wanted to know whether offering the options of "accepts" and "imagines" would lead people to not select "believes." The purpose of including two conditions was to check whether participants would continue to attribute belief even when the story did not explicitly use the word "believe."

\subsection{Results}

No participant in either condition checked "denies" or "rejects," as is appropriate in light of the details of the story, so we will not discuss either of those options any further (see Fig. 7). Chi square tests for independence revealed that participants attributed belief more in the Believe condition (57 of 60, or 95\%) than in the Accept condition $(41$ of 61 , or $67 \%), \chi^{2}(1,121)=15.17, p<.001$; participants attributed acceptance more in the Accept condition (47 of 61, or $77 \%$ ) than in the Believe condition (22 of 60 , or $37 \%), \chi^{2}(1,121)=20.13, p<.001$; but there was no effect of condition on how frequently participants attributed imagining (Believe: 28 of 60 , or $47 \%$; Accept: 34 of 61 , or $56 \%), \chi^{2}(1,121)=1.00, p=.365$, or how frequently participants attributed knowledge (Believe: 11 of 60, or 18\%; Accept: 18 of 61, or $30 \%), \chi^{2}(1,121)=2.07, p=.201$. The differences in belief and acceptance attribution indicate that people are more likely to attribute a mental state when the agent explicitly says that he chooses to be in the mental state. Nevertheless, Chi square goodness of fit tests revealed that a statistically significant majority of participants attributed belief in both the Believe condition, $\chi^{2}(1,60)=48.60$, $p<.001$, and the Accept condition, $\chi^{2}(1,61)=7.23, p=.007$. McNemar's tests revealed that participants were more likely to attribute belief than acceptance in the 


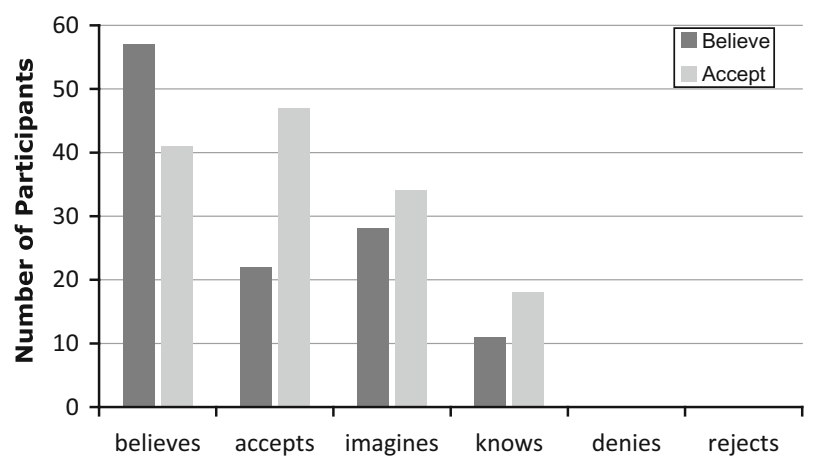

Fig. 7 Experiment 6. Number of participants who attributed the several mental states in a "check all that apply" task, across two conditions in which the agent stated that he chose to "believe" or "accept" a proposition

Believe condition, $p<.001$, but the proportion attributing those two states did not differ in the Accept condition, $p=.327$. McNemar's tests also revealed that participants were more likely to attribute belief than imagining in the Believe condition, $p<.001$, and marginally more likely to do the same in the Accept condition, $p=.092$.

\subsection{Discussion}

The principal finding emerging from this experiment is that people continued to attribute voluntary belief when given the option of attributing "acceptance" or "imagining" instead. Moreover, a significant majority of people attributed voluntary belief even when the agent did not mention "belief" but instead described himself as choosing to "accept" the relevant proposition. These findings address the objection that earlier results were due to task demand because of limited answer options, thereby further strengthening the evidence that voluntary belief is conceptually possible.

\section{Summary of experimental results}

Overall, the results clearly demonstrate that folk psychology views belief as voluntary. Experiments $1 \mathrm{~A}$ and $1 \mathrm{~B}$ provide evidence that belief is viewed not only as voluntary but also as the most voluntary mental state of the ten we tested. Experiments 2 and 3 provide evidence that strong-willed agents are more readily viewed as voluntarily believing than weak-willed agents, and this effect persists across extremely different levels (5 vs 95\%) of evidence. Indeed, level of evidence had almost no effect on whether belief was viewed as voluntary. Experiment 4 provides evidence that evidential source affects the extent to which belief is viewed as voluntary. Inferential belief is more readily judged voluntary than perceptual belief. But even in cases involving perception, people do not outright reject the 
possibility of voluntary belief. Instead, they clearly judge that one can voluntarily choose to believe but are ambivalent as to whether one can refuse to believe on the basis of perceptual evidence. Experiment 5 provides evidence that people readily attribute voluntary belief that is "immediate" and "actual," and that they view the formation of such beliefs very differently from performing an impossible task. Experiment 6 provides evidence that people readily attribute voluntary belief even when they could instead attribute acceptance or imagining, and even when the word "believe" does not appear in the story.

\section{Conclusion}

An enduring philosophical dispute is whether belief can be voluntary. Involuntarists have offered conceptual and psychological arguments in favor of their view. Given the centrality of belief in folk psychology, if voluntary belief is a "chokingly unswallowable" conceptual impossibility, then ordinary practice will reject it and betray an implicit commitment to involuntarism. But if folk psychology countenances voluntary belief, then voluntary belief is a conceptual possibility and we have some positive evidence that voluntary belief is a psychological reality. Our results demonstrate that folk psychology countenances voluntary belief and perhaps even views belief as the most voluntary of propositional attitudes. It follows that conceptual arguments for involuntarism fail. Our results also provide evidence that psychological arguments for involuntarism probably fail too. Given minimal charitable assumptions about the competence manifested in ordinary folk-psychological judgments, our results make it likely that at least some belief (and disbelief) is voluntary. Overall, then, our results suggest that voluntary belief is not only possible but also actual. These are important results about a perennial philosophical question.

In concluding our discussion, we will reply to several objections, try to charitably reconstruct the intuitions that led philosophers to mistakenly endorse conceptual arguments for involuntarism, and highlight some implications of our findings for future research in this area.

\subsection{Objections and replies}

Involuntarists might charge folk psychology with "deep conceptual confusion" (Pojman 1985, p. 53) and consequently dismiss our results. But given the current state of evidence, this charge is implausible. It is possible to acquire evidence that a central class of folk psychological judgments is badly mistaken. For example, "situationist" social psychologists have amassed evidence which, many argue, shows that our ordinary practices of trait-attribution and action-explanation are often badly mistaken (for an overview, see Ross and Nisbett 2011; see also Harman 1999; Doris 2002). We overestimate the prevalence of stable global character traits (such as honesty or courage) and we underestimate the role of situational factors in explaining human behavior. But despite several decades of empirical results and convergent lines of evidence from dozens if not hundreds of researchers around the 
world, not even the staunchest situationist claims that no one ever has stable global character traits or that such traits never actually explain behavior. Much less would they claim that these things are conceptually impossible. In short, massive amounts of evidence were required for psychologists and philosophers to seriously propose that these folk practices are mostly erroneous, but even that massive amount of evidence is still inadequate to conclude that trait-possession is psychologically or conceptually impossible. In our estimation, this serves as a model of honest inquiry into the limiting conditions of familiar but incompletely understood psychological phenomena. Doxastic involuntarists in philosophy would do well to bear in mind this chapter of contemporary intellectual history.

Involuntarists might abandon claims of conceptual impossibility and instead, noting that conceptual possibility is an imperfect guide to genuine possibility (Arnauld 1641/2006), argue that belief is involuntary by its nature, by analogy with emotion or digestion. Voluntary emotion or digestion is not conceptually impossible but by their nature emotion and digestion are involuntary states (for humans, at least). Call this the essentialist argument for involuntarism. Our results do not rule out the essentialist argument, but we view it as little more than speculation rendered improbable by existing research. Research suggests that to some extent humans can voluntarily control their emotions (Beauregard et al. 2001; Ochsner and Gross 2005) and that Tibetan monks can voluntarily control their heart rate (e.g. Lehrer et al. 1999). If basic emotional and physiological responses can be and sometimes are under voluntary control, then there is no reason to expect that belief is essentially involuntary (Naylor 1985).

Involuntarists might try to reduce voluntarism to absurdity. If we can voluntarily believe despite the absence of evidence, and even contrary to the evidence, then cases of severe clinical delusions could count as beliefs; but surely severe clinical delusions are not beliefs; so there must be something wrong with the voluntarist position we have defended here. In response, the reductio assumes far too much about the nature of delusions. Clinical psychologists and psychiatrists actually define delusions as beliefs (American Psychiatric Association 2000). We doubt it is an accident that professionals who deal most closely with delusional patients choose to define delusion as belief. Moreover, recent research has shown that folk psychology categorizes severe clinical delusions as clear examples of belief (Rose et al. 2014).

Involuntarists might restrict their thesis so that it applies only to a specific type of belief in certain contexts, and then argue that our results do not pertain to the restricted thesis. For example, involuntarists might restrict their view to, among other things, consciously formed beliefs relevant to deciding how to act in the context (e.g. Frankish 2007, pp. 532, 536-7). In response, the agents in the scenarios we tested fit the relevant description. Someone who explicitly deliberates out loud and then adopts the attitude clearly does so consciously and actively. These are not cases of "the passive acquisition" of unconscious beliefs (Frankish 2007, p. 536). And the content of the attitude was relevant to the agent's behavior in the scenarios. For instance, in Experiments 5 and 6, Eric states, "I choose to believe that we can do the impossible," in a context where a political leader tells him that this attitude is required to fix "serious problems facing" the community. People strongly agreed 
that Eric formed the relevant belief. Independently of that, we would also like to note that restricted involuntarist views are also defended on the alleged grounds that they are "close to a conceptual truth ... for conscious belief" (Frankish 2007, p. 537), which comes close to claiming that it should be obvious to anyone competent with the concept. Moreover, the argument that allegedly rules out voluntary belief formation "because we cannot complete an infinite series of acts" (Levy and Mandelbaum 2014, p. 17; Frankish 2007, p. 533) assumes that voluntary beliefs of a relevant sort are impossible. So this argument cannot be legitimately used to call into question the relevance of our results, or our participants' competence. $^{6}$

Finally, involuntarists might instead adopt a prescriptive strategy. Instead of arguing that our actual concept of belief rules out the possibility of voluntary belief, they could argue that we should adopt a conception of belief which does rule it out. Or, alternatively, they could argue that we should abandon talk and thought of belief in favor of some other propositional attitude which, conceptually, is necessarily involuntary. Our research was not intended to engage with prescriptive involuntarism and we have no response to it, aside from wondering what motivation there could possibly be for choosing to believe it.

\subsection{Explaining involuntarist sentiment}

Some very intelligent and accomplished theorists have thought that there is something, let us say, conceptually suspicious about voluntary belief. But given our clear results in favor of doxastic voluntarism, it seems that we are left with attributing massive error to those who have endorsed doxastic involuntarism. We greatly respect these thinkers and would like to charitably reconstruct a motivation for their view. So our task in this section will be to propose two hypotheses about the source of involuntarist sentiment. We consider two views about the nature of concepts and apply them to the concept BELIEF, ${ }^{7}$ in an attempt to understand why many philosophers might have been tempted to view belief as involuntary. On either of these views, the motivation for doxastic involuntarism is intelligible even if, as we have argued, conceptual and psychological arguments for the impossibility of voluntary belief fail.

Before proceeding, we want to be absolutely clear about one thing: in the debate between voluntarists and involuntarists, any need for charitable reconstruction goes both ways. We acknowledge some obligation to explain why many of our esteemed and intelligent opponents in this debate were so badly mistaken about the concept of belief. But involuntarists are also left with attributing massive conceptual error to the likes of Augustine, Aquinas, Descartes, and James, to name just a few. So, by the same token, involuntarists incur an obligation of charitable reconstruction too.

\footnotetext{
6 The argument also assumes a principle about intention formation- "the Control Principle" (Frankish 2007, p. 534) — which is also said to be "intuitively plausible," but which we think is dubious.

7 We use SMALl CAPS to denote concepts.
} 
Having clarified that, in an effort to discharge our obligation, we will now present our hypotheses.

First, BELIEF might be a prototype or family-resemblance concept (Wittgenstein 1953; Rosch and Mervis 1975). Instead of comprising a "checklist" of necessary and sufficient conditions (Fillmore 1975), BELIEF might summarize the central tendency of the category of beliefs. This central tendency will consist of a cluster of properties that a prototypical belief has. Some of these properties matter more, are more central, to the category. A belief similar to the prototype is typical but a belief dissimilar to the prototype is atypical, just as a robin is typical of birds but a penguin is atypical. Suppose that prototypical belief is involuntary. It follows that a voluntary belief cannot be typical in the fullest sense. More ambitiously, suppose that involuntariness is a centrally important feature of the prototype, akin to flight for birds. It follows that a voluntary belief could always be viewed as importantly atypical. This could explain why involuntarists sensed something conceptually suspicious about voluntary belief.

If BELIEF is a prototype concept, then we can understand the temptation to view belief as involuntary. But even if BELIEF is a prototype concept, some of our results suggest that involuntariness is not a centrally important feature of BELIEF. For instance, in Experiment 3 participants were happy to attribute belief in cases where the agent "chooses to believe" that it's raining upon learning that there is a $5 \%$ chance that it will rain. Similarly, participants were perfectly happy to attribute nonbelief when the agent "refuses to believe" that it's raining upon learning that there is a $95 \%$ chance that it will rain. Although our participants were happy to answer this way, response rates were neither at ceiling in the first case nor at floor in the second. Further work could compare cases where an agent chooses (refuses) to believe to cases where the agent feels compelled to believe (withhold judgment). If people attribute belief significantly more (less) in the latter than in the former, then that would be some evidence that prototypical belief is involuntary. Given our results, even if involuntariness turns out to be a feature of prototypical belief, we doubt that it is a centrally important feature. By contrast, our results do not provide evidence against the more specific hypothesis that prototypical perceptual belief is involuntary.

Second, BELIEF might be a dual character concept (Knobe et al. 2013). Dualcharacter concepts are associated with two ways to determine category membership. On the one hand, the "concrete" mode determines membership in terms of observable or functional features. For instance, someone trained in a lab to conduct experiments, analyze data, test theories, and publish papers is a scientist. On the other hand, the "abstract" mode determines membership normatively. The point of conducting experiments, analyzing data, etc., is to promote the systematic acquisition of empirical knowledge. Crucially, the criteria associated with the concrete mode are "ways of realizing" the value embodied in the abstract mode. SCIENTIST is a dual character concept.

A hallmark of dual character concepts is that even though something satisfies the concrete criteria, it can still seem like there is a sense in which it does not ultimately or truly belong in the category. Consider someone trained in a lab to conduct experiments, analyze data, etc., but who dogmatically clings to a single hypothesis 
no matter how the evidence turns out. It can seem right to say that he is not truly a scientist. That is because he satisfies the concrete criteria in a way that inhibits the abstract value's realization. By contrast, suppose that someone operates a public bus, opens and closes its door, transports passengers, etc. He is a public bus driver. The goal of public transportation is to promote the citizenry's convenience and well-being, or something thereabout. Even if the bus driver's activities do not promote convenience and well-being, it does not seem right to say that he is not truly a bus driver. BUS DRIVER is not a dual character concept.

Thus dual character concepts enable us to view something as both a member and as a non-member of the category. It can be a member in virtue of concrete or functional considerations while seeming like a non-member in virtue of abstract or normative considerations. In short, it can seem like something is a member of the category but not truly a member of the category.

Suppose that BELIEF is a dual character concept. Its concrete criteria might include causing relevant bodily actions, assertions, affect, and inferences, and having a word-to-world direction of fit (Lewis 1980; Schwitzgebel 2011; Anscombe 1957). Its abstract value might be the acquisition of true and useful information for use in planning, instruction and coordination (Turri in press). Satisfying the concrete criteria are ways of realizing the abstract value. Beliefs could satisfy the concrete criteria in ways that inhibit the abstract value's realization. For example, voluntary belief acquisition might inhibit acquiring true information, as Bernard Williams suggests when he writes that he cannot view a voluntary state as "a belief of mine" because he cannot "seriously think of it ... as something purporting to represent reality" (Williams 1973, p. 148). A state acquired voluntarily is acquired "irrespective of the truth" and, thus, is not truly a belief.

As with the prototype view, the dual-character view of concepts would explain why doxastic involuntarists sensed something conceptually suspicious about voluntary belief. If belief is a dual character concept, then it could seem right to say that voluntary beliefs are not truly beliefs. And this would be true due to a feature of the concept of belief.

Of course, we should not rule out the possibility that there are individual and cultural differences in how people understand the abstract values associated with belief or how those values relate to belief's concrete features. Neither should we rule out that such differences help to explain the incidence of involuntarist sentiment among philosophers. Academic intellectuals might place a much higher premium on truth and evidence than people ordinarily do. Taken far enough, this added emphasis, reinforced by values prevalent within the subculture of academic philosophy, could lead to conceptual change (Thagard 1990; Kuhn 1962/2012). More specifically, prolonged attempts to understand the nature of belief, in the context of a culture where truth and evidence are prized above all other values associated with belief, could have changed how some philosophers conceive of the abstract values associated with belief and, therefore, how they attribute it. These philosophers are the involuntarists. Involuntarists and laypeople could both have a dual character concept of belief, even though the two concepts differ in the abstract values and how they relate to the concrete features. 
We emphasize that our two hypotheses about the source of involuntarist sentiment are speculative. On either hypothesis, belief is conceptually connected to involuntariness, though not in a way that renders voluntary belief impossible. It is an interesting empirical question whether either of these hypotheses best characterizes the concept of belief and, in turn, identifies a kernel of insight in involuntarism. Other explanations are also possible. But regardless of how that empirical question turns out, our results strongly support doxastic voluntarism.

\subsection{Implications for future work on voluntary belief}

Our findings have implications for future work on voluntarism. Conceptual arguments for involuntarism should no longer be taken seriously and further progress in this area will begin by simply leaving such arguments behind. Indeed, at this point, to continue believing that voluntary belief is conceptually impossible might well be a performative contradiction: it verges on an existence proof of voluntary belief. Similarly, because doxastic involuntarism is not a conceptual truth, there is no point in trying to "explain why" it is a conceptual truth. In our estimation, the only remaining conceptual question is to identify the features of the concept of belief which misled so many insightful people to think that voluntary belief is impossible (see Sect. 3.2).

We have provided noteworthy positive evidence against psychological arguments for involuntarism. This evidence derives from carefully controlled behavioral experiments involving hundreds of participants, multiple replications, diverse stimuli, and diverse dependent measures. But this evidence is, of course, fallible and future empirical findings could suggest new psychological arguments for involuntarism. We welcome and encourage further relevant empirical work in this area, including work that utilizes a broader range of methods from cognitive science and work that ends up providing new evidence for psychological arguments for involuntarism. Nevertheless, any such argument incurs the burden of explaining why folk psychology is so badly mistaken about belief's relationship to the will.

Aside from our findings' intrinsic interest and importance, they have consequences for other philosophical debates. For example, many epistemologists convinced of involuntarism have drawn conclusions about the nature of epistemic evaluation or epistemic justification. Some have argued that if belief is involuntary, then epistemic justification is not deontological, and if epistemic justification is not deontological, then it undermines the motivation for internalist theories of epistemic justification (Alston 1989; Plantinga 1993). Others have accepted that involuntarism is true for perceptual belief but not inferential belief and have concluded that epistemic justification is "bifurcated" (Weatherson 2008). Our results deprive these arguments against internalism and for bifurcation of their force. Of course, there could still be good independent reasons to reject internalism or accept bifurcation. To take another example, philosophers of religion have noted that involuntarism has implications for what divine beings can rightfully demand of us (Vitz 2008). If involuntarism is true, then a good god could not punish people who do not choose to believe the tenets of a certain religion. One unhappy consequence of voluntarism, then, is that weighty doxastic demands made by angry gods are not automatically 
illegitimate in virtue of the concept of belief. Of course, there could still be other reasons why such divine demands are illegitimate.

Acknowledgements For helpful feedback, we thank Carolyn Buckwalter, Carl Ginet, Joshua Knobe, Shaun Nichols, Jonathan Schaffer, and Angelo Turri. Thanks also to an audience at Cornell University and this journal's anonymous referees. This research was supported by the Social Sciences and Humanities Research Council of Canada, the Ontario Ministry of Economic Development and Innovation, and the Canada Research Chairs program.

\section{References}

Alston, W. P. (1988). The deontological concept of epistemic justification. Philosophical Perspectives, 2, 257-299.

Alston, W. P. (1989). Epistemic justification: Essays in the theory of knowledge. Ithaca: Cornell University Press.

American Psychiatric Association. (2000). Diagnostic and statistical manual of mental disorders (4th ed.). Arlington County: American Psychiatric Publishing.

Anscombe, G. E. M. (1957). Intention. Oxford: Blackwell.

Arnauld, A. (1641/2006). Fourth set of objections. In R. Ariew \& D. Cress (Ed. \& Trans.), Meditations, objections, and replies. Indianapolis: Hackett.

Baldwin, D. A, \& Tomasello, M. (1998). Word learning: A window on early pragmatic understanding. In E. V. Clark (Ed.), The proceedings of the twenty-ninth annual child language research forum. Stanford: Center for the Study of Language and Information.

Baron-Cohen, S. (1995). Mindblindness: An essay on autism and theory of mind. Cambridge, MA: MIT Press.

Bartsch, K., \& Wellman, H. M. (1995). Children talk about the mind. Oxford: Oxford University Press.

Beauregard, M., Lévesque, J., \& Bourgouin, P. (2001). Neural correlates of conscious self-regulation of emotion. The Journal of Neuroscience, 21, 1-6.

Bennett, J. (1990). Why is belief involuntary? Analysis, 50, 87-107.

Buckareff, A. A. (2004). Acceptance and deciding to believe. Journal of Philosophical Research, 29, 173-190.

Buckareff, A. A. (2006). Doxastic decisions and controlling belief. Acta Analytica, 21, 102-114.

Buckwalter, W., Rose, D., \& Turri, J. (2015). Belief through thick and thin. Nous, 49(4), 748-775. doi:10. 1111 /nous.12048.

Chisholm, R. (1964). Human freedom and the self. Lawrence: University of Kansas.

Cohen, L. J. (1992). An essay on belief and acceptance. Oxford: Oxford University Press.

Descartes, R. (1644/1985). The principles of philosophy. In J. Cottingham, R. Stoothoff, \& D. Murdoch (Trans.), The philosophical writings of Descartes (Vol. 1). Cambridge: Cambridge University Press.

Doris, J. M. (2002). Lack of character: Personality and moral behavior. Cambridge: Cambridge University Press.

Egan, A. (2009). Imagination, delusions, and self-deception. In T. Bayne \& J. Fernández (Eds.), Selfdeception and affective influences on belief-formation (pp. 263-280). Hove: Psychology Press.

Ellis, P. (2010). The essential guide to effect sizes: Statistical power, meta-analysis and the interpretation of research results. Cambridge: Cambridge University Press.

Feldman, R. (2001). Voluntary belief and epistemic evaluation. In M. Steup (Ed.), Knowledge, truth, and duty (pp. 77-92). Oxford: Oxford UP.

Feldman, R. (2007). Modest deontologism in epistemology. Synthese, 161(3), 339-355.

Fillmore, C. J. (1975). An alternative to checklist theories of meaning. In Proceedings of the annual meeting of the Berkeley Linguistics Society (pp. 123-131).

Fodor, J. (1987). Psychosemantics. Cambridge, MA: MIT Press.

Frankish, K. (2007). Deciding to believe again. Mind, 116(463), 523-548. doi:10.1093/mind/fzm523. 
Ginet, C. (2001). Deciding to believe. In Matthias Steup (Ed.), Knowledge, truth and duty (pp. 63-76). Oxford: Oxford University Press.

Gopnik, A., \& Meltzoff, A. (1997). Words, thoughts and theories. Cambridge, MA: MIT Press.

Harman, G. (1999). Moral philosophy meets social psychology: Virtue ethics and the fundamental attribution error. Proceedings of the Aristotelian Society, 99, 315-331.

Heller, M. (2000). Hobartian voluntarism: Grounding a deontological conception of epistemic justification. Pacific Philosophical Quarterly, 81, 130-141. doi:10.1111/1468-0114.00099.

Hieronymi, P. (2006). Controlling attitudes. Pacific Philosophical Quarterly, 87(1), 45-74.

Hieronymi, P. (2009). Believing at Will. Canadian Journal of Philosophy, 39(supplemental issue), $149-188$.

Hobbes, T. (1641/2006). Third set of objections, by a famous English philosopher. In R. Ariew \& D. Cress (Ed. \& Trans.), Meditations, objections, and replies. Indianapolis: Hackett.

James, W. (1948). The will to believe. In A. Castell (Ed.), Essays in pragmatism (pp. 88-109). New York: Hafner Press.

Johnston, M. (1995). Self-deception and the nature of mind. In C. MacDonald \& G. MacDonald (Eds.), Philosophy of psychology. Cambridge, MA: Blackwell.

Kitcher, P. S. (1984). In defense of intentional psychology. Journal of Philosophy, 81, 89-106.

Knobe, J., Prasada, S., \& Newman, G. E. (2013). Dual character concepts and the normative dimension of conceptual representation. Cognition, 127(2), 242-257. doi:10.1016/j.cognition.2013.01.005.

Kuhn, T. S. (1962/2012). The structure of scientific revolutions. Chicago: University of Chicago Press.

Lahav, R. (1992). The amazing predictive power of folk psychology. Australasian Journal of Philosophy, 70, 99-105.

Lehrer, P., Sasaki, Y., \& Saito, Y. (1999). Zazen and cardiac variability. Psychosomatic Medicine, 61(6), 812-821.

Leslie, A. (1992). Autism and the 'theory of mind' module. Current Directions in Psychological Science, $1,18-21$.

Levy, N., \& Mandelbaum, E. (2014). The powers that bind: doxastic voluntarism and epistemic obligation. In J. Matheson \& R. Vitz (Eds.), The ethics of belief (pp. 15-32). Oxford: Oxford University Press.

Lewis, D. (1980). Mad pain and Martian pain. In N. Block (Ed.), Readings in philosophy of psychology (Vol. 1). Cambridge: Harvard.

Malle, B. F. (2003). The social cognition of intentional action. In P. W. Halligan, C. Bass, \& D. A. Oakley (Eds.), Malingering and illness deception (pp. 83-92). Oxford: Oxford University Press.

McCabe, K., Smith, V., \& Lepore, M. (2000). Intentionality detection and 'mindreading': Why does game form matter? Proceedings of the National Academy of Sciences, 94, 4404-4409.

Montmarquet, J. (1986). The voluntariness of belief. Analysis, 46, 49-53.

Naylor, M. B. (1985). Voluntary belief. Philosophy and Phenomenological Research, 45(3), 427-436.

Ochsner, K., \& Gross, J. (2005). The cognitive control of emotion. Trends in Cognitive Sciences, 9(5), 242-249. doi:10.1016/j.tics.2005.03.010.

O'haughnessy, B. (1980). The will. Cambridge: Cambridge University Press.

O'Neill, D. K., Astington, J. W., \& Flavell, J. H. (1992). Young children's understanding of the role that sensory experiences play in knowledge acquisition. Child Development, 63(2), 474-490. doi:10. 1111/j.1467-8624.1992.tb01641.x.

Perner, J. (1991). Understanding the representational mind. Cambridge, MA: MIT Press.

Plantinga, A. (1993). Warrant and proper function. Oxford: Oxford University Press.

Pojman, L. P. (1985). Believing and willing. Canadian Journal of Philosophy, 15(1), 37-55.

Pojman, L. P. (Ed.). (1999). Believing, willing, and the ethics of belief. In The theory of knowledge (2nd ed.). Belmont, CA: Wadsworth.

Rosch, E., \& Mervis, C. B. (1975). Family resemblances: Studies in the internal structure of categories. Cognitive Psychology, 7(4), 573-605. doi:10.1016/0010-0285(75)90024-9.

Rose, D., Buckwalter, W., \& Turri, J. (2014). When words speak louder than actions: Delusion, belief and the power of assertion. Australasian Journal of Philosophy, 92(4), 683-700. doi:10.1080/00048402. 2014.909859.

Rose, D., \& Schaffer, J. (2013). Knowledge entails dispositional belief. Philosophical Studies. doi:10. 1007/s11098-012-0052-z.

Ross, L., \& Nisbett, R. E. (2011). The person and the situation: Perspectives of social psychology. London: Pinter \& Martin.

Ryan, S. (2003). Doxastic compatibilism and the ethics of belief. Philosophical Studies, 114(1), 47-79. 
Scheines, R. (1997). An introduction to causal inference. In V. McKim \& S. Turner (Eds.), Causality in crisis (8th ed., pp. 185-200). Notre Dame: University of Notre Dame Press.

Schwitzgebel, E. (2011). Mad belief? Neuroethics, 5(1), 13-17.

Scott-Kakures, D. (1994). On belief and captivity of the will. Philosophy and Phenomenological Research, 54, 77-103.

Shah, N. (2002). Clearing space for doxastic voluntarism. The Monist, 85(3), 436-445.

Steup, M. (2008). Doxastic freedom. Synthese, 161(3), 375-392.

Thagard, P. (1990). Concepts and conceptual change. Synthese, 82(2), 255-274. doi:10.1007/ BF00413664.

Turri, J. (2015a). Skeptical appeal: The source-content bias. Cognitive Science, 39(2), 307-324. doi:10. $1111 / \operatorname{cogs} .12153$.

Turri, J. (2015b). An open and shut case: Epistemic closure in the manifest image. Philosophers' Imprint, $15(2), 1-18$.

Turri, J. (in press). Sustaining rules: A model and application. In J. A. Carter, E. C. Gordon, \& B. Jarvis (Eds.), Knowledge first. Oxford: Oxford University Press.

Van Fraassen, C. (1984). Belief and the will. The Journal of Philosophy, 81(5), 235-256.

Vitz, R. (2008). Doxastic voluntarism. In J. Fieser \& B. Dowden (Eds.), Internet encyclopedia of philosophy. Retrieved November 2013, from http://www.iep.utm.edu/doxa-vol/

Wang, J. J., Miletich, D. D., Ramsey, R., \& Samson, D. (2014). Adults see vision to be more informative than it is. Quarterly Journal of Experimental Psychology, 67(12), 2279-2292. doi:10.1080/ 17470218.2014.915331.

Wellman, H. (1990). The child's theory of mind. Cambridge, MA: MIT Press.

Weatherson, B. (2008). Deontology and Descartes's demon. Journal of Philosophy, 105(9), 540-569.

Williams, B. (1973). Deciding to believe. In Bernard Williams (Ed.), Problems of the self. Cambridge: Cambridge University Press.

Winters, B. (1979). Believing at will. Journal of Philosophy, 76, 243-256.

Wittgenstein, L. (1953). Philosophical investigations. (G. E. M. Anscombe, Trans.). Oxford: Basil Blackwell. 